\title{
The Associations Between Oxytocin and Trauma in Humans: A Systematic Review
}

\author{
Mariana Fortunata Donadon ${ }^{1}$, Rocio Martin-Santos ${ }^{2,3,4}$ and Flávia de Lima Osório ${ }^{1,4 *}$ \\ ${ }^{1}$ Department of Neuroscience and Behavior, Medical School of Ribeirão Preto, University of São Paulo, São Paulo, Brazil, \\ ${ }^{2}$ Department of Psychiatry and Psychology, Hospital Clínic, Institut d'Investigacions Biomèdiques August Pi i Sunyer \\ (IDIBAPS), Centro de Investigación en Red de Salud Mental (CIBERSAM), Barcelona, Spain, ${ }^{3}$ Department of Medicine, \\ University of Barcelona, Barcelona, Spain, ${ }^{4}$ Technology Institute for Translational Medicine (INCT), National Council for \\ Scientific and Technological Development (CNPq), Brasilia, Brazil
}

Studies have shown that traumatic experiences may affect hormonal systems mediated by the hypothalamic-pituitary-adrenal (HPA) axis and the oxytocinergic system. This effect is the result of long-term impairments in hypothalamic structures and negative feedback mechanisms within the HPA axis, structures that mediate the response to stress. This deregulation reduces the production and release of cortisol and oxytocin (OXT), which may alter stress responses and lead to increased vulnerability to impairments from stressful experiences. The presence of gene polymorphisms might also have an impact on the vulnerability to psychopathology. We made a systematic review of articles dealing with the relationship between OXT and traumatic emotional experiences in humans. Thirty-five studies were reviewed and significant associations between experiences of emotional trauma (ET) and OXT were found. The main results showed that the presence of ET and post-traumatic stress disorder (PTSD) is strongly associated with reductions in endogenous OXT, and also that the acute effects of OXT administrations in individuals with ET tend to be anxiolytic only in less severe forms. In victims of recent traumatic experiences (RTE), OXT increased the re-experience of traumas and restored the function of different neural networks associated with fear control/extinction in PTSD patients. The results available also suggest that gene receptor polymorphisms may have a protective function in different outcomes after the experience of traumatic events. We conclude that the relationship between ET and OXT is multifaceted, complex, and mediated by contextual and individual factors. Directions for future studies are suggested considering the gaps in the available literature.

Keywords: oxytocin, early trauma, current trauma, PTSD, systematic review, PRISMA, qualitative assessment

\section{INTRODUCTION}

Traumatic and stressful experiences throughout life, whether acute or chronic, may lead to changes in different bodily systems that increase the vulnerability to psychopathology (Meewisse et al., 2007; McQuaid et al., 2016). One of the most well-known of such changes concerns hormonal systems, including the hypothalamic-pituitary-adrenal (HPA) axis. The HPA axis plays a fundamental role in responding to both external and internal stimuli, including psychological stressors, and is also believed to be implicated in vulnerability to mental illnesses (Heinrichs et al., 2003; Juruena et al., 2004; Boyce and Ellis, 2005; Neumann and Landgraf, 2012; Olff, 2012; Kuhlman et al., 2015). 
When facing stressful situations, especially during the early stages of development, the HPA axis can be either hypoor hyperactived, with the possibility of excessive exposure to glucocorticoids and their deleterious effects. These effects can persist throughout the lifespan because as the HPA axis may remain unstable, hypersensitive, or dysfunctional. This contributes to the weakening of the immune system, to increased vulnerability to different physical and mental illnesses, and to the inability to cope with subsequent stressful/traumatic events that may lead to exhaustion of the organism (Mirescu et al., 2004; Smith and Vale, 2006; Faravelli et al., 2012).

Several neurotransmitters and neuropeptides also affect the function of the HPA axis, including oxytocin (OXT). OXT is a neurohormone produced in the hypothalamus by the supraoptic and paraventricular nuclei. It is sent to the posterior pituitary or neurohypophysis and, from there, it is secreted into the bloodstream to produce its effects (Gimpl and Fahrenholz, 2001). OXT has peripheral and central functions and its action in breastfeeding, childbirth and maternal behavior is well established (Ring et al., 2006; Yoshida et al., 2009; Neumann and Landgraf, 2012).

In addition to these functions, OXT has therapeutic potential associated with the promotion of pro-social behaviors such as increased self-confidence, positive social memories, and affiliative behavior. Furthermore, previous studies have investigated the possibility that the administration of OXT may lead to reductions in anxiety and stress levels (Savaskan et al., 2008; Guastella et al., 2009; Rimmele et al., 2009; Ross and Young, 2009; Fischer-Shofty et al., 2010).

Existing evidence suggests that central OXT release contributes to the modulation and maintenance of cortisol levels that favor the rapid return of the body to its prestress baseline state (Amico et al., 2004; Gulpinar and Yegen, 2004; Heinrichs et al., 2004) to minimize the response of the HPA axis to psychologically stressful stimuli. However, stressful experiences might also alter the functioning of the suprachiasmatic nucleus, decreasing the synthesis and release of endogenous OXT (Ozbay et al., 2008; Gonzalez et al., 2009; Nicolson et al., 2010). As result, the negative feedback mechanism of the HPA axis may be affected, leading to hypercortisolemia (Yehuda et al., 2000; Brown et al., 2016). On the behavioral level, the decrease in endogenous OXT levels reduces the multiple pro-social functions of this hormone, thereby reducing coping and resiliency responses (Opacka-Juffry and Mohiyeddini, 2012; Frijling et al., 2015 ).

In light of the above findings, the release of exogenous administration of OXT can reduce hormonal and subjective responses to stress, reduce cortisol release in the blood stream, and reestablish bodily homeostasis, therefore placing OXT as a potential therapeutic agent (Cardoso et al., 2013, 2014). Another line of research deals with the role that genetic polymorphisms play in OXT receptor genes, which might alter the individual vulnerability to stress since changes in receptor configuration can reduce or prevent the binding of OXT and its consequent effects in the body (Champagne and Curley, 2009; Skuse and Gallagher, 2011; Unternaehrer et al., 2012; Bakermans-Kranenburg and van IJzendoorn, 2014).
As seen, a number of recent studies have attempted to provide a detailed understanding of the multiple and complex associations between OXT and different traumatic and stressful situations, whether chronic or acute (Myers et al., 2014; Seltzer et al., 2014; Mizushima et al., 2015; Van Zuiden et al., 2017). The objective of the current study was to systematically review this literature to highlight the major contributions of the studies conducted to date dealing with the associations between OXT and traumatic emotional experiences in humans.

\section{METHODOLOGY}

The guidelines of the Preferred Reporting Items for Systematic Reviews and Meta-Analyses (PRISMA-Moher et al., 2009) were adopted as the methodological framework of this study. The electronic databases PsycINFO, PubMed, Scielo, Web of Science, and LILACS were searched without limitations in terms of time, language, or publication date (last search conducted on December 3, 2017). A manual search of the reference lists of the selected articles was also performed. The following keywords were used followed by "AND" or "OR:" oxytocin; PTSD; post-traumatic stress; early trauma; childhood maltreatment; emotional trauma; emotional stress; neglect; adversity; sexual abuse; emotional abuse; and physical abuse.

Articles that evaluated associations between OXT and the experience of early trauma (ET), recent traumatic experiences (RTE), and post-traumatic stress disorder (PTSD) in men and women, regardless of age, were eligible for inclusion. ET experiences were considered as those that occurred before 18 years of age (Bremner et al., 2000), and RTEs were considered as those that occurred over the last few days or months (Chatzittofis et al., 2014).

Studies of endogenous OXT that did not involve participants with ET, RTE, or PTSD; those investigating OXT and psychiatric disorders excluding PTSD; those involving OXT and social behavior, resilience, social cognition, genetic analysis, and the physiological aspects of the HPA axis among participants without ET, RTE, or PTSD; those involving treatment for ET or PTSD but not involving OXT; and animal studies, letters to the editor, case studies, and reviews unrelated to this topic were excluded.

Two researchers made independent decisions regarding whether to include a study, and divergences in data extraction were discussed until a consensus was reached.

Figure 1 shows the search results as well the reasons for article exclusion.

The methodological quality of the studies was evaluated using the following references: (a) Strengthening the Reporting of Observational Studies (STROBE; Von Elm et al., 2007); (b) Transparent Reporting of Evaluations with Non-Randomized Designs (TREND; Des Jarlais et al., 2004); and (c) the Revised Recommendations for Improving the Quality of Reports of Parallel-Group Randomized Trials (CONSORT; Moher et al., 2001). The quality percentage of each study was calculated by dividing the number of items scored by the total number of items. 


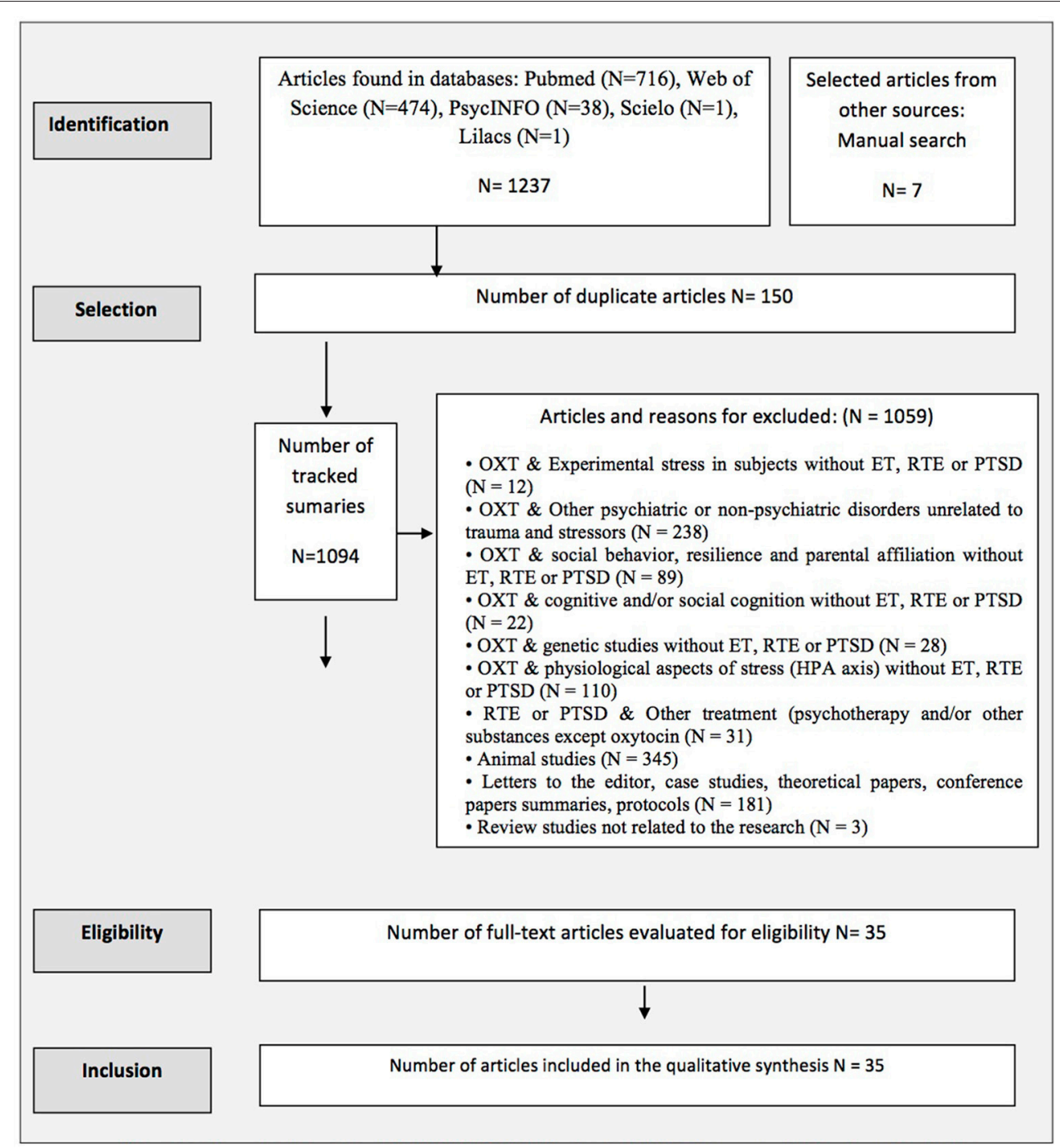

FIGURE 1 | Flowchart based on PRISMA/(OXT, Oxytocin; ET, Early trauma; HPA, Hypothalamic Legend Pituitary Adrenal Axis; PTSD, Post traumatic stress disorder; RTE, Recent trauma event).

\section{RESULTS}

A total of 1,244 articles were found, and 35 articles were selected after applying the inclusion and exclusion criteria (see Figure 1).

Table 1 below presents the main characteristics of the included studies in relation to the samples, outcomes assessment, and methodological quality. For more details, see the Excel dataset in the Supplementary Material (S1).

Importantly, regarding the methodological quality evaluation, all of the studies included in this review had at least $64 \%$ of their essential items included in the STROBE (observational studies), TREND (experimental studies) or CONSORT [experimental or randomized controlled trials (RCTs)].

Depending on their designs or objectives, the studies were divided into four distinct groups: (a) observational studies evaluating endogenous OXT levels; (b) experimental studies related to the reactivity of the oxytocinergic system; (c) RCTs of OXT administration and the experience of either ET, RTE, or PTSD; and (d) observational studies investigating the effect of polymorphisms of the OXT receptor gene.

The major results of each study group are presented below.

(a) Observational studies evaluating endogenous OXT levels.

The association between endogenous OXT levels and ET situations was evaluated by six studies as a major outcome. Four of these studies found significant correlations between endogenous OXT levels and ET, with values ranging from -0.54 to -0.23 (Heim et al., 2009; Opacka-Juffry and Mohiyeddini, 2012; Chatzittofis et al., 2014; Mohiyeddini et al., 2014). On the contrary, Mizushima et al. (2015) did not find an association between OXT levels and experiencing ET $(p>0.05 ; d=0.19$; insignificant effect size). Importantly, however, OXT secretions 


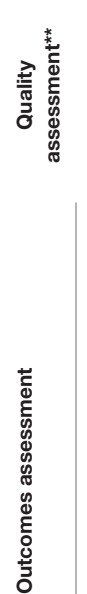

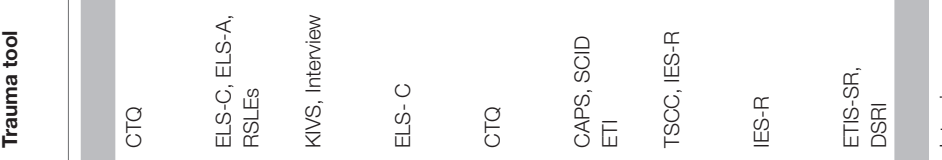

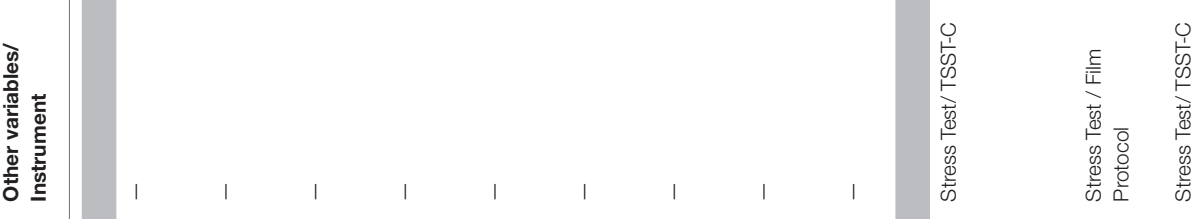

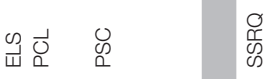

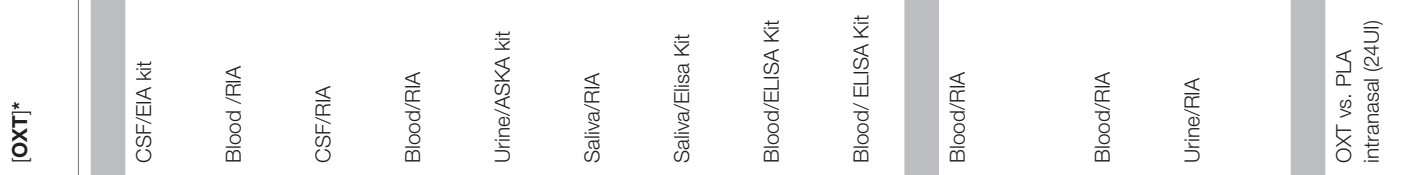
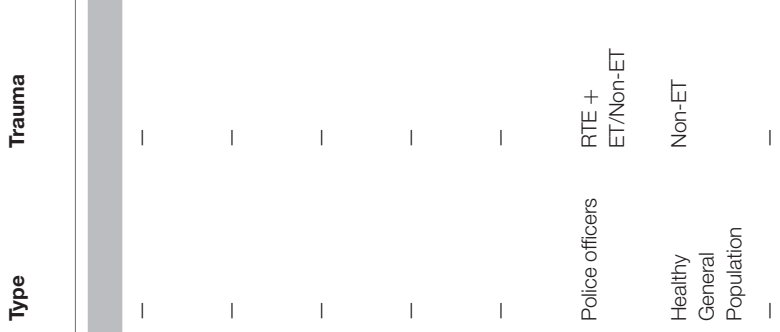

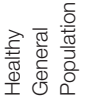

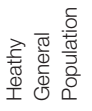

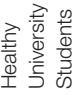

这

迹

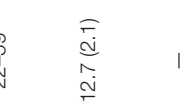

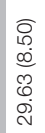

z

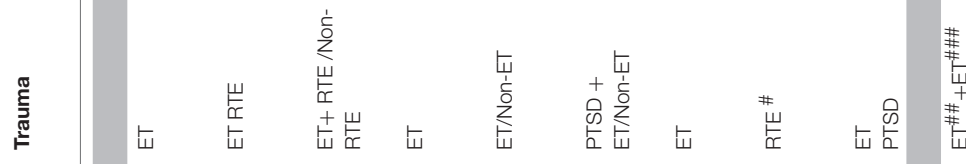

$\sum \underset{ }{\stackrel{4}{N}}$

5
2

装

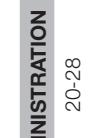

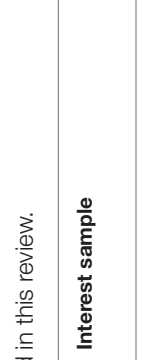

$$
\text { (1) }
$$

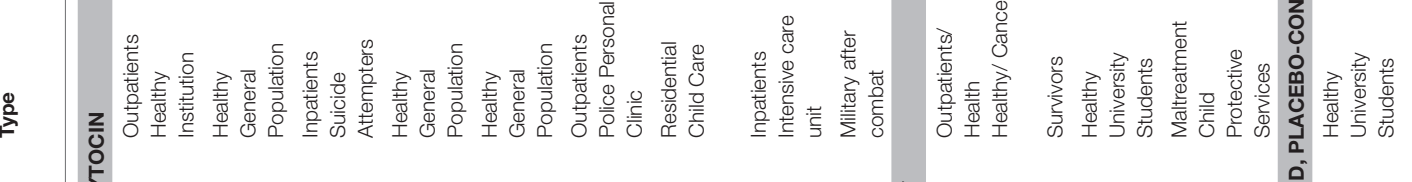

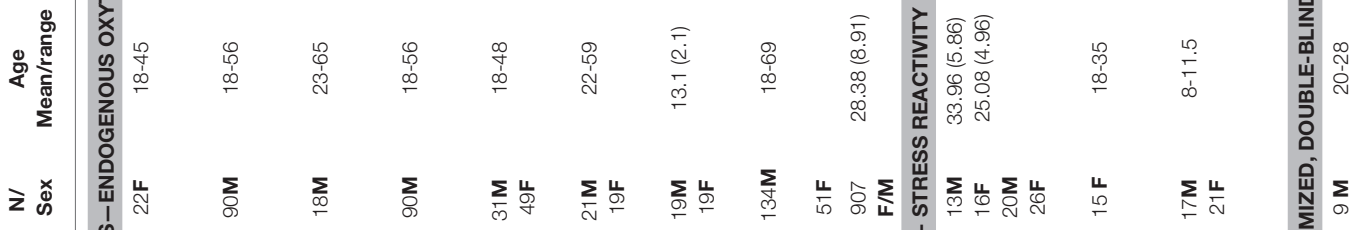

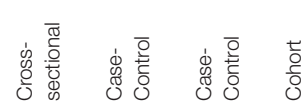

(1)
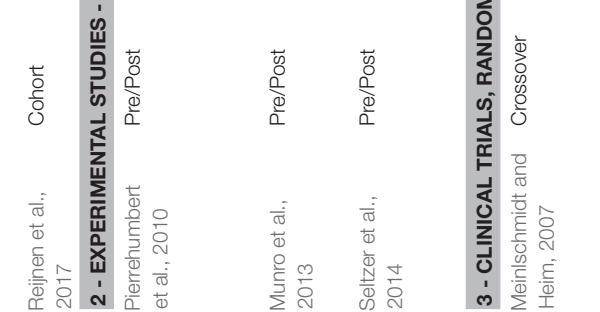


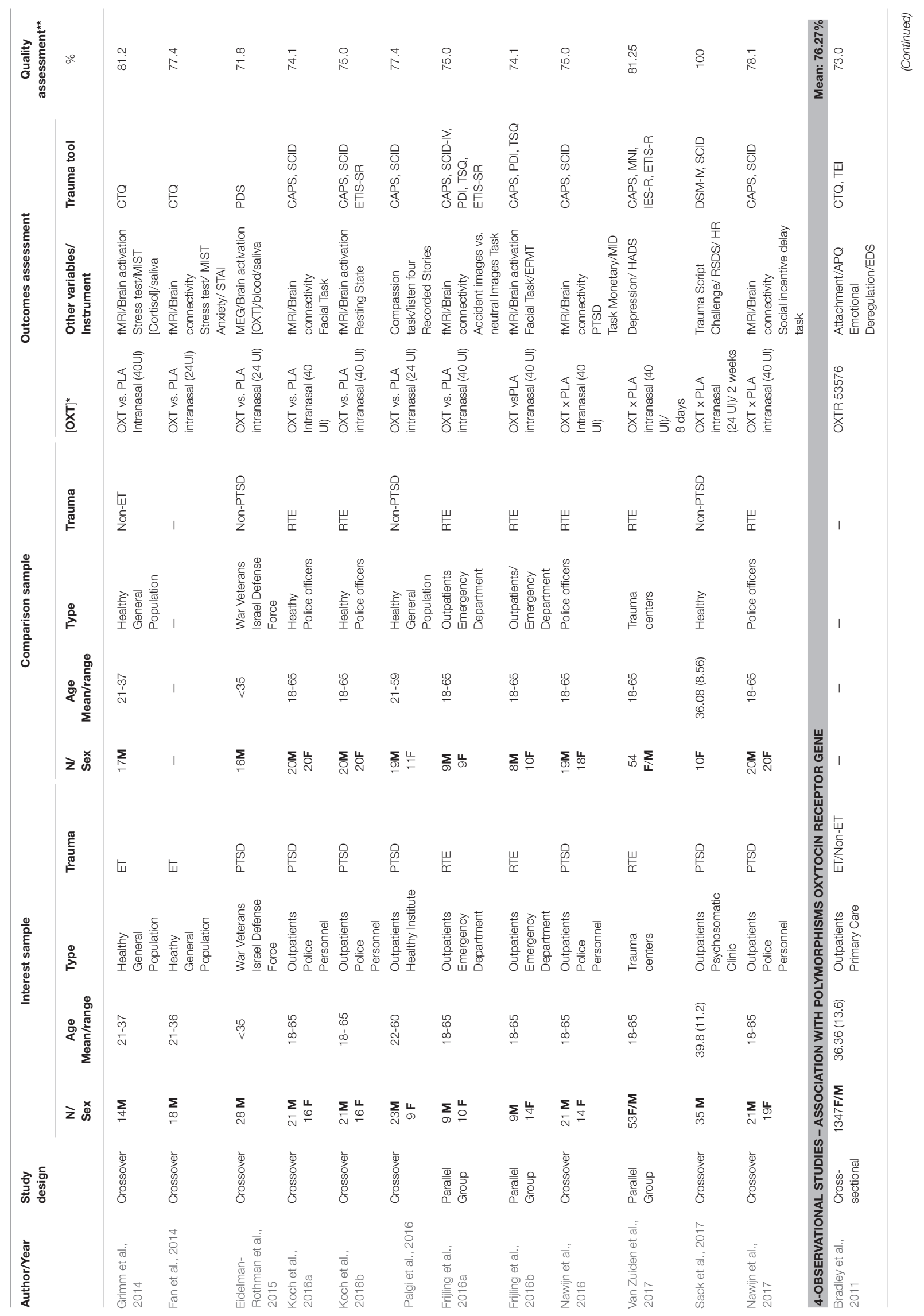




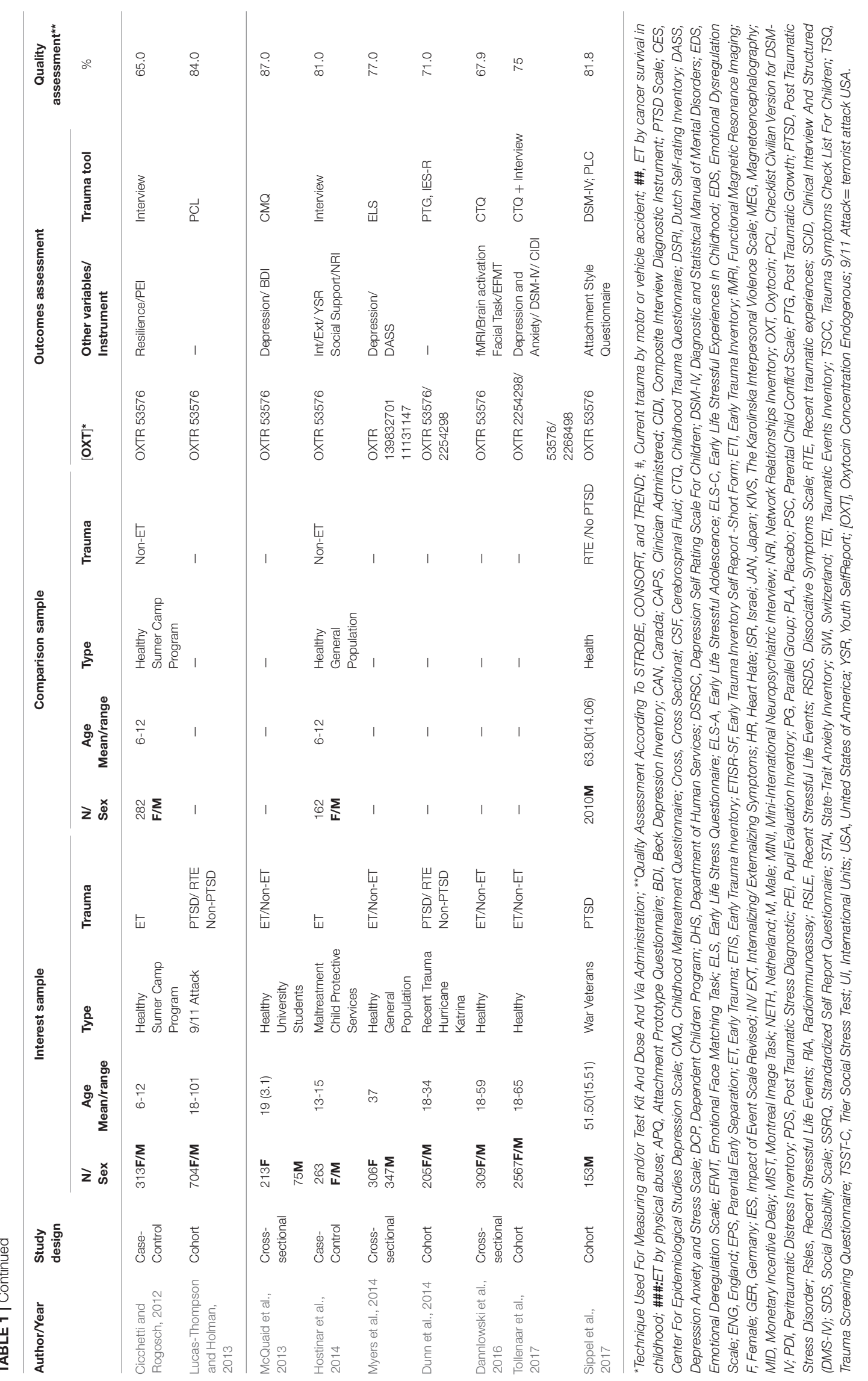


were markedly increased in adolescents who suffered abuse and lived in a stable environment (e.g., a social welfare institution) at the time of the experiment from awakening to bedtime compared with those who had a history of abuse and lived in unstable environments. Mizuki and Fujiwara (2015) showed that only less severe forms of ET were associated with increased OXT levels.

Heim et al. (2009) also performed complementary analyses to evaluate the effect of the recurrence of traumatic events. These authors found that experiencing three or more types of traumatic events during childhood was related with reduced endogenous OXT levels, with a moderate effect size $\left(\mathrm{n}_{p}{ }^{2}=0.45\right)$. OpackaJuffry and Mohiyeddini (2012) also conducted complementary analyses and found associations between decreased endogenous OXT levels and increased emotional suppression $(\mathrm{r}=-0.30$, $p<0.01$ ) during adulthood.

Studies that evaluated participants with RTEs failed to find any significant correlations. For example, Opacka-Juffry and Mohiyeddini (2012) found that the correlation between OXT and RTE was $0.01(p>0.05)$. Chatzittofis et al. (2014) also failed to find an association between endogenous OXT levels and RTEs $(r=-0.30, p=0.18$ ); however, these authors found that endogenous OXT levels were lower in individuals with RTEs who also experienced ET (i.e., were re-victimized) than in those who only experienced trauma during childhood ( $p=0.04)$.

Nishi et al. (2015) also failed to find an association between PTSD symptoms and endogenous OXT levels $(r=-0.08$ to $-0.00, p>0.57)$. However, these authors showed interesting differences between the genders: In women, endogenous OXT levels were positively correlated with cooperativeness $(r=0.41$, $p=0.01$ ), whereas in men these levels were negatively correlated with C-reactive protein $(r=-0.22, p<0.01)$, which indicates that OXT plays a role in the coping strategies for PTSD symptoms among women.

The findings of Frijling et al. (2015) also indicated gender differences. Regarding endogenous OXT levels in highly traumatized police officers, only men with PTSD showed lower levels of OXT than those without PTSD ( $p$
$<0.05, d=0.60$; moderate effect size). No differences were observed in women ( $p>0.05 ; d=0.10$; insignificant effect size).

Finally, a recent study by Reijnen et al. (2017) found that predeployment OXT levels in soldiers sent to Afghanistan did not predict PTSD development. However, the experience of an ET predicted the development of PTSD, even though no associations were found between OXT levels and the presence/absence of ET in these individuals.

(b) Experimental studies relating to the reactivity of the oxytocinergic system.

Three studies evaluated OXT levels (reactivity patterns) in acute stressful situations, although these results should be interpreted with caution because of their small sample sizes (Table 2).

Girls who experienced physical abuse during childhood showed increased reactivity to stress. In other words, they presented with higher levels of endogenous OXT after undergoing an acute stress test $(p=0.02)$, whereas OXT levels in boys with and without a history of physical abuse did not change after stress induction (Seltzer et al., 2014). On the other hand, adults with a history of sexual abuse (regardless of gender) showed decreasing OXT levels after acute stress (Pierrehumbert et al., 2010).

Munro et al. (2013) also found a decrease in OXT levels after exposure to abandonment scenes $(p=0.01)$ but not after exposure to bonding scenes $(p=0.39)$. However, associations were observed between increased OXT levels and increased dissociative, somatic, and attachment symptoms during bonding scenes as well as between decreased OXT levels and PTSD symptoms during abandonment scenes.

\section{(c) RCTs of OXT administration and trauma.}

The results of these trials were grouped by the type of trauma experienced and are shown in Table 3.

TABLE 2 | Major results of endogenous OXT during experimental studies (reactivity to stress) of participants who experienced trauma $(n=3)$.

\begin{tabular}{|c|c|c|c|c|c|}
\hline \multirow[t]{2}{*}{ Study } & \multirow{2}{*}{$\begin{array}{l}\text { Type of } \\
\text { stress test }\end{array}$} & \multicolumn{4}{|c|}{ Results } \\
\hline & & [OXT] situation & Reactivity to stress & $r$ & $p$ \\
\hline \multirow[t]{2}{*}{$\begin{array}{l}\text { Pierrehumbert } \\
\text { et al., } 2010\end{array}$} & TSST-C & Pre-Stress [OXT] & $\begin{array}{l}\text { ET sexual abuse = ET cancer } \\
\text { childhood = control }\end{array}$ & - & 0.23 \\
\hline & & Post-Stress (+20 min) [OXT] & ET sexual abuse $<$ control & - & 0.06 \\
\hline \multirow[t]{3}{*}{ Munro et al., 2013} & $\begin{array}{l}\text { Film Protocol } \\
\text { (Abandonment } \\
\text { and Bond }\end{array}$ & Bonding [OXT] & $\begin{array}{l}\text { Basal } \rightarrow \text { Bonding }=\text { no alterations } \\
\text { Dissociation symptoms } \times \text { higher } \\
\text { levels [OXT] }\end{array}$ & 0.55 & $\begin{array}{l}0.39 \\
0.018^{\star}\end{array}$ \\
\hline & scenes) & & $\begin{array}{l}\text { Somatization symptoms } \times \text { higher } \\
\text { levels [OXT] }\end{array}$ & 0.59 & $0.010^{*}$ \\
\hline & & Abandonment [OXT] & Basal $\rightarrow$ Abandonment $=\downarrow$ & - & $0.01^{*}$ \\
\hline
\end{tabular}

[OXT], oxytocin; ET, Early trauma; PTSD, Post-traumatic stress disorder; ơ, Men; o, Women; TSST-C, Trier Social Stress Test; < Minor; > Major. *Difference statistically significant. 
TABLE 3 | Major results of RCTs that administered OXT to participants who experienced early or current trauma $(N=13)$.

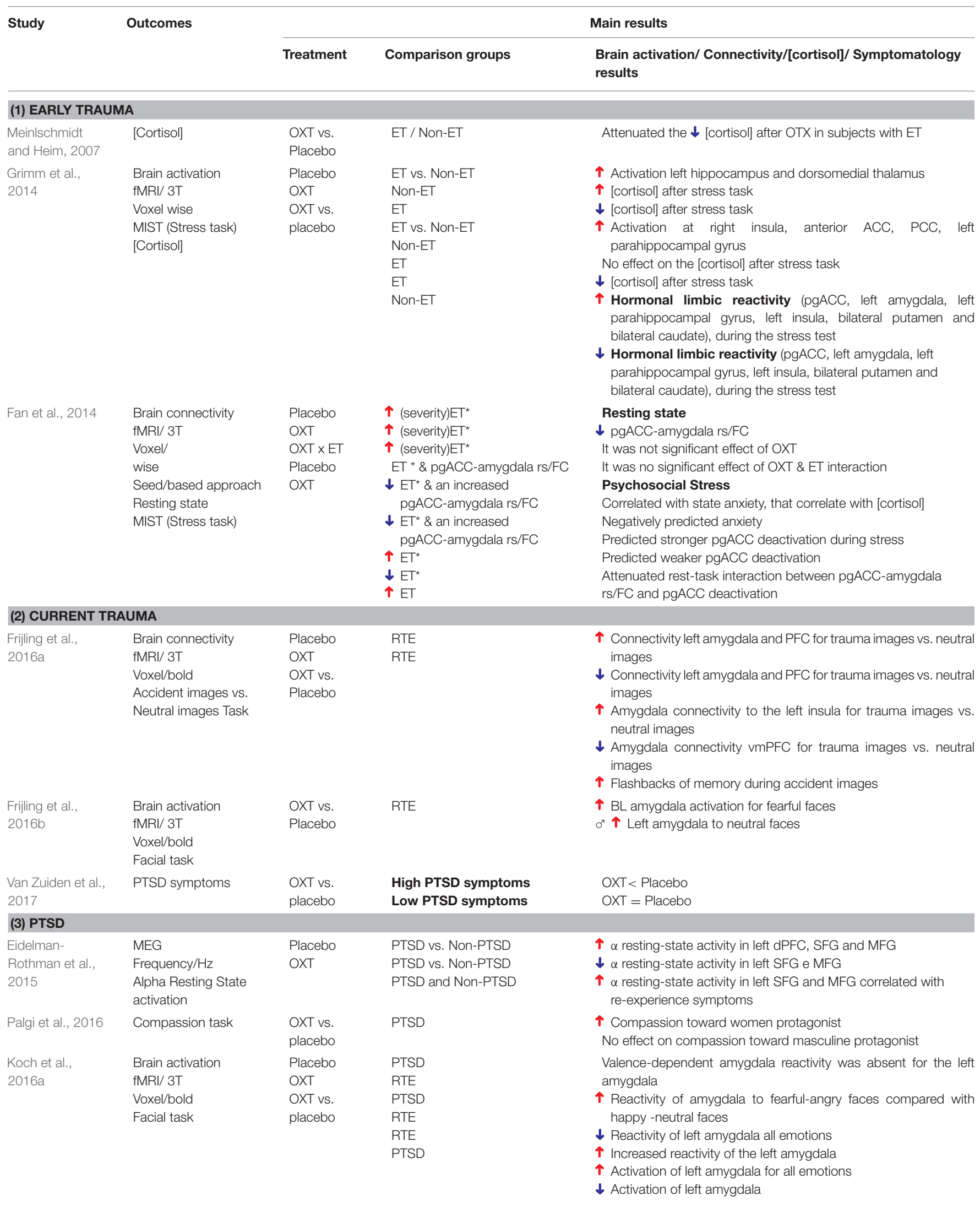


TABLE 3 | Continued

\begin{tabular}{|c|c|c|c|c|}
\hline \multirow[t]{2}{*}{ Study } & \multirow[t]{2}{*}{ Outcomes } & \multicolumn{3}{|r|}{ Main results } \\
\hline & & Treatment & Comparison groups & $\begin{array}{l}\text { Brain activation/ Connectivity/[cortisol]/ Symptomatology } \\
\text { results }\end{array}$ \\
\hline $\begin{array}{l}\text { Koch et al., } \\
2016 b\end{array}$ & $\begin{array}{l}\text { Brain connectivity } \\
\mathrm{fMRI} / 3 \mathrm{~T} \\
\text { Voxel/bold } \\
\text { Resting State }\end{array}$ & $\begin{array}{l}\text { Placebo } \\
\text { OXT }\end{array}$ & 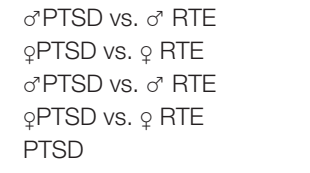 & $\begin{array}{l}\downarrow \text { Connectivity right CeM amygdala to left vmPFC } \\
\uparrow \text { Connectivity right BLA to bilateral dACC } \\
\uparrow \text { Connectivity right CeM to left vmPFC } \\
\downarrow \text { Connectivity right BLA to right dACC } \\
\downarrow \text { Anxiety and nervousness but not happiness and sadness }\end{array}$ \\
\hline $\begin{array}{l}\text { Nawijn et al., } \\
2016\end{array}$ & $\begin{array}{l}\text { Brain activation } \\
\mathrm{fMRl} / 3 \mathrm{~T} \\
\text { Voxel/bold } \\
\text { Task/Monetary }\end{array}$ & $\begin{array}{l}\text { Placebo } \\
\text { OXT vs. } \\
\text { placebo }\end{array}$ & PTSD and RTE Non-PTSD & $\begin{array}{l}\uparrow \text { Reaction time on MID task for reward/loss vs. neutral trials } \\
\uparrow \text { Brain activation at ventral striatum, amygdala, insula, CPF } \\
\text { orbitofrontal } \\
\uparrow \text { Brain activation at right striatum, dACC, and insula during } \\
\text { reward and loss }\end{array}$ \\
\hline Sack et al., 2017 & $\begin{array}{l}\text { Trauma Script } \\
\text { Challenge }\end{array}$ & OXT & PTSD & $\begin{array}{l}\downarrow \text { reduced avoidance symptoms } \\
\text { No effect on re-experiencing and dissociative symptoms } \\
\uparrow \text { Heart rate }\end{array}$ \\
\hline $\begin{array}{l}\text { Nawijn et al., } \\
2017\end{array}$ & $\begin{array}{l}\text { Brain activation } \\
\mathrm{fMRl} / 3 \mathrm{~T} \\
\text { Social Task }\end{array}$ & $\begin{array}{l}\text { Placebo } \\
\text { OXT } \\
\text { OXT vs. } \\
\text { Placebo }\end{array}$ & $\begin{array}{l}\text { PTSD vs. RTE Non-PTSD } \\
\text { PTSD vs. RTE Non-PTSD } \\
\text { PTSD }\end{array}$ & $\begin{array}{l}\downarrow \text { Activation insula anterior left during social incentive } \\
\uparrow \text { Activation bilateral putamen, right dACC and right insula during } \\
\text { social incentive } \\
\uparrow \text { Activation right Putamen during social incentive } \\
\uparrow \text { Activation left striatum; right striatum and insula, and right } \\
\text { dorsal ACC }\end{array}$ \\
\hline
\end{tabular}

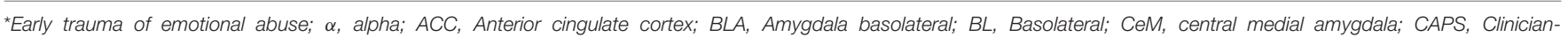

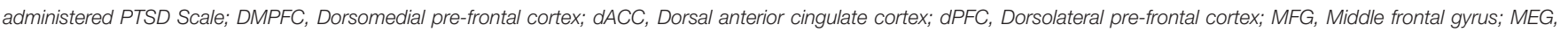

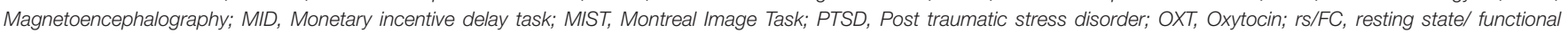

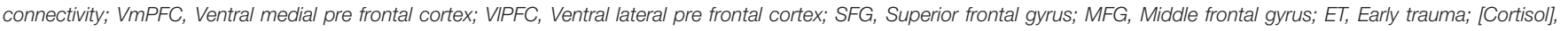

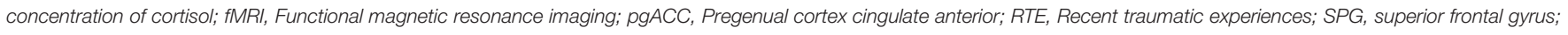
sgACC, Subgenual anterior cingulate cortex.

Three studies evaluated participants with just ET. In the first, Meinlschmidt and Heim (2007) measured endogenous cortisol and demonstrated that intranasal OXT attenuated the cortisol decrease in participants with ET compared with controls, suggesting the presence of amortization effects related to HPAaxis activities. In the other two studies, participants with ET were assessed in the context of a psychosocial stress situation, and the results indicated that negative outcomes were associated with acute OXT administration.

In one of these studies, Grimm et al. (2014) found that participants with ET, regardless of severity, presented with greater hormonal and limbic reactivity after the use of OXT. However, Fan et al. (2014) found that the activation of the connectivity between the amygdala and the pregenual anterior cingulate cortex (pgACC) during stress was only attenuated by OXT in individuals with less severe ET. The use of OXT did not favor this anxiolytic effect in patients with moderate-to-severe ET.

Two studies by Frijling et al. (2016a,b) reported the adverse effects of exogenous OXT administration in individuals with RTEs. In one such study (Frijling et al., 2016a), OXT administration during threatening situations reduced the functional connectivity between the left amygdala and the ventrolateral prefrontal cortex (vlPFC) as well as between the amygdala and the ventromedial prefrontal cortex (vmPFC) circuits responsible for cognitive-emotional regulation and fear extinction. These findings were also accompanied by an increased connectivity between the amygdala and the insula as well as increased episodes of traumatic flashbacks. In the other study (Frijling et al., 2016b), increased amygdala reactivity was elicited by fearful faces, indicating that OXT favors an increase in the processing of fear salience and, consequently, anxiogenic effects.

A single study administered OXT for eight subsequent days and showed that it did not attenuate PTSD symptoms in the short term (45 days). However, only participants with high symptom severity reported improvement after 6 months, which suggests that OXT may has a protective effect in the long term which is mediated by symptom severity (Van Zuiden et al., 2017). In this study, as well as at Fan et al. (2014), it is evident the influence of the severity of experience/symptoms of trauma.

Contrary to the effects observed in subjects with RTE, in those with a PTSD installed, the related effects to acute OXT administration were favorable. Eidelman-Rothman et al. (2015) examined veterans with PTSD and showed that OXT normalized the resting-state brain functioning of these individuals, which was similar to those of controls (i.e., veterans not exposed to trauma). Prior to exogenous OXT administration, an increase in resting-state alpha activity was observed in the left dorsolateral prefrontal cortex (dPFC), especially in the superior frontal gyrus (SFG) and middle frontal gyrus (MFG). These regions are associated with memory and cognitive control, which are important for emotional control.

Koch et al. (2016a,b) and Nawijn et al. (2016, 2017) examined the same sample of participants (i.e., trauma-exposed police 
officers with or without PTSD), in different paradigms outcomes and showed positive effects during acute OXT administration. In a resting state paradigm the acute OXT effects were different between genders. In men with PTSD, OXT decreased subjective anxiety and nervousness as well as restored the connectivity between right amygdala (CeM) and the left vmPFC. In women, OXT restored the connectivity between the right basolateral amygdala (BLA) and the anterior cingulate dorsal cortex (dACC), which decreased the anxiety and fear expression originating from the amygdala (Koch et al., 2016b). In an emotional face-matching task, the acute effects of OXT in subjects with PTSD were the same, regardless of gender: OXT reduced amygdala reactivity to all emotional expressions. In those without RTE, however, reactivity was increased, which indicates the presence of the anxiolytic effects of OXT only in trauma-exposed individuals who develop PTSD (i.e., an interdependence of inter-individual factors; Koch et al., 2016a). During a monetary task, OXT increases neural responses during anticipation of reward or loss in key regions of the brain's reward circuit (i.e., the striatum, dACC, and insula) and decreases motivational anhedonia. These effects were positively associated with those of OXT in the ventral striatum (Nawijn et al., 2016). Similarly, during a social incentive delay task, the administration of OXT normalized the aberrant insula response and increased the putamen response, indicating increased neural sensitivity to social reward (Nawijn et al., 2017). Finally, it was observed as positive effects related to OXT, an increase in compassion toward women with PTSD (Palgi et al., 2016) and a decrease in the avoidance symptoms during trauma script exposure (Sack et al., 2012).

(d) Observational studies investigating the effect of the polymorphisms of the OXT receptor gene.

The major polymorphism studied was OXTR rs53576, which was evaluated in $88.8 \%$ of the included studies. Table 4 shows the main results found.

Regarding the results linked to the OXTR rs53576 gene polymorphism, participants who exhibited the GG genotype and experienced ET, PTSD, or both reported a series of impairments including emotional dysregulation and problematic attachment (Bradley et al., 2011), PTSD symptoms (Lucas-Thompson and Holman, 2013), symptoms of depression (McQuaid et al., 2013), lower levels of perceived social support, and internalized behavioral problems (Hostinar et al., 2014). Using structural magnetic resonance, Dannlowski et al. (2016) showed that the presence of the $\mathrm{G}$ allele (GG/GA) was associated with increased amygdala responsiveness to all emotional facial expressions (negative and positive), constituting a higher vulnerability to alterations in the limbic brain structure in individuals with ET. Furthermore, a negative correlation was found between ventral striatum gray matter volume and participants with ET and the GG genotype.

Cicchetti and Rogosch (2012) showed that the presence of ET and the AA/AG genotype was associated with increased resiliency; therefore, the presence of the AA/AG genotype appears to have a protective function. On the other hand, Tollenaar et al. (2017) indicated that the OXTR53576 gene polymorphism does not interact with ET and predict risk factor and/or vulnerability toward the development of depression or anxiety. In addition, Sippel et al. (2017) found that the presence of a minor allele associated with an insecure attachment style was associated with a higher prevalence of PTSD among war veterans.

Other polymorphisms studied included OXTR rs2254298 and rs2268498, but neither Dunn et al. (2014) nor Tollenaar et al. (2017) found changes or association among the presence of ET or PTSD, a single nucleotide polymorphism, and the development of symptoms. In addition, Dunn et al. (2014) investigated the role of rs53576 and did not find a difference between the presence of the AA allele and the AG or GG alleles as risk factors for the development of PTSD or its symptoms.

Finally, one study evaluated the polymorphisms OXTR rs139832701 and rs11131147. This study showed that participants who experienced ET and had these polymorphisms exhibited higher levels of depression and more symptoms of stress (Myers et al., 2014).

\section{DISCUSSION}

The present review revealed associations between traumatic experiences in humans and the neuropeptide OXT that involve polymorphisms on OXT receptor genes. These associations are multiple and complex and are mediated by contextual and inter-individual factors. A stronger association with OXT was found with regard to the experience of early or chronic trauma as well as with recurrent, severe, or intense traumatic events. Regarding RTEs, the association was strong among individuals who developed psychopathological conditions (e.g., PTSD).

The findings of the group of studies that evaluated endogenous OXT levels showed a moderate association between reduced OXT levels and the experience of trauma. This finding supports the hypothesis that early adversity persistently, even up to adulthood, alters the functioning of the suprachiasmatic nucleus, which is responsible for the production and release of OXT (Ozbay et al., 2008; Gonzalez et al., 2009; Nicolson et al., 2010; Goldman-Mellor et al., 2012). This change might favor vulnerability to stress during adulthood and impair the social functioning associated with OXT. Moreover, it might reduce coping and resiliency responses (Opacka-Juffry and Mohiyeddini, 2012; Frijling et al., 2015). Interestingly, Munro et al. (2013) showed that an increase in endogenous OXT was associated with symptoms of social detachment, which might not always result in favorable outcomes (Seng, 2010).

However, an increase in endogenous OXT occurred in participants with ET and specific conditions such as less severe forms of ET and social environmental change (from a threatening environment to a protective environment with the establishment of stable social relationships). This finding shows the role of OXT in the development and maintenance of resiliency (Elzinga et al., 2008; Carpenter et al., 2009; Heim et al., 2009). Authors such as Mizuki and Fujiwara (2015) and Mizushima et al. (2015) suggested that an increase in OXT occurs as a response to social stress, thereby promoting the regulation of the oxytocinergic system and an increase in pro-social behaviors under challenging and less unfavorable situations. These findings also reinforce 
TABLE 4 | Main results of the association studies of early or current trauma with regard to OXT receptor gene polymorphisms $(N=10)$.

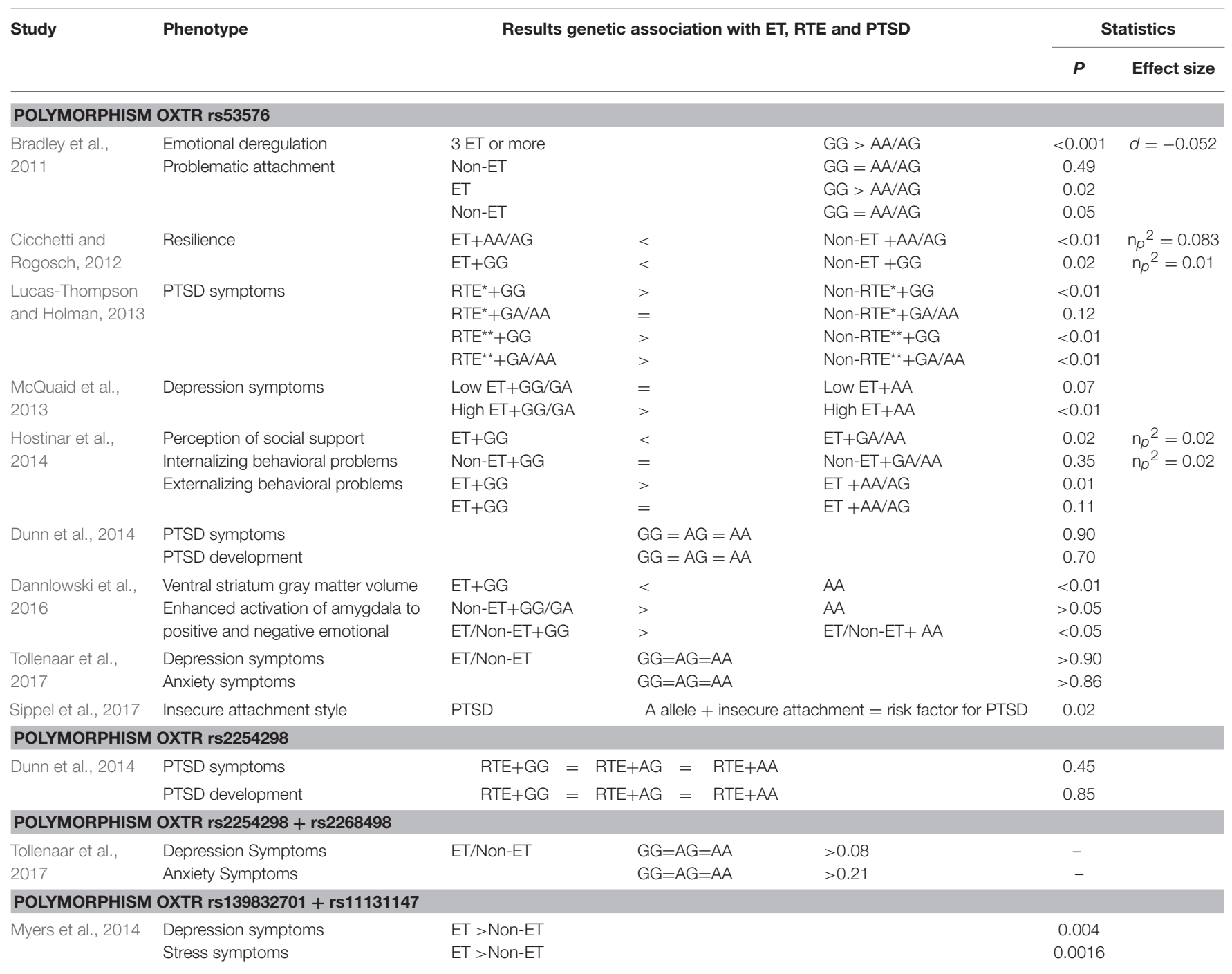

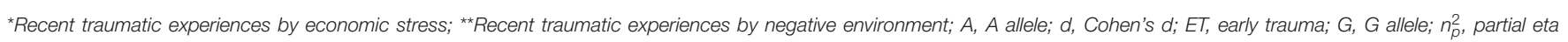
squared; PTSD, post-traumatic stress disorder; p, level of significance; Non-ET, absence of early trauma; RTE, Recent traumatic experiences.

Veenema (2012) views concerning the high plasticity of the oxytocinergic system and its dependence on social cues.

Studies have indicated the mediating role that other variables play in traumatic situations during adulthood because OXT is reduced only in subjects with ET and/or PTSD, demonstrating decreased resiliency responses. It has also been suggested that stress affects the oxytocinergic system in a sex-dependent manner (see especially Nishi et al., 2015), which has been extensively documented in animals (Ebner et al., 2000; Cameron et al., 2008).

The studies related to stress reactivity have also shown gender dependence because only women with a history of physical abuse show increased OXT secretion under acute stress (Seltzer et al., 2014). When gender was not experimentally controlled, a decrease in OXT secretion was observed (Munro et al., 2013). Previous studies have shown that men and women differ with regard to the release of endogenous OXT following behavioral paradigms. They also differ behaviorally after exogenous OXT administration (Finkelhor et al., 1990; Heim et al., 2000; Seng et al., 2014; Feng et al., 2015; Koch et al., 2016a,b).

One possible explanation of the above gender effects might involve the biochemical differences in the number of available OXT receptors between men and women as well as the binding affinity of these receptors in specific neural networks (UhlBronner et al., 2005; Hoge et al., 2014). Furthermore, the different phases of the menstrual cycle can also influence OXT levels as well as the HPA axis, conferring more or less impairment (Altemus et al., 2001). This effect is seen because of the role of estrogen, which regulates the production of OXT receptors and the possible release of this hormone (Williams et al., 1985; Wigger and Neumann, 1999). In contrast, evidence also shows that androgens inhibit OXT release under stress (Young et al., 1997). According to Taylor et al. (2006), OXT might also favor the 
"tend and befriend" response in women and the "fight or flight" response in men.

The results of the studies that focused on exogenous OXT administration varied by the type of stressor. Regarding ET, the effect of this stressor on the functioning of the brain circuits was demonstrated. ET favored functional changes in the brain circuits, especially those associated with limbic regions (e.g., the hypothalamus, pgACC, amygdala, and parahippocampal gyrus), which are HPA axis-modulating regions. In this sense, OXT modulates the neural networks to favor an improved response to stress (Meinlschmidt and Heim, 2007).

Other studies that examined severe ET, however, seemed to show a null or differential response to exogenous OXT administration that assumes anxiogenic characteristics. This effect might occur because of previous changes in the oxytocinergic circuit as a consequence of the traumatic experience or because of unregulated interactions between the oxytocinergic system and the other neurotransmitter systems (Fan et al., 2014; Grimm et al., 2014).

The effects of exogenous OXT in individuals with RTE at risk for PTSD were unfavorable because they tended to promote anxiogenic effects and did not reduce the risk of developing different pathologies, including PTSD. The results generally showed that OXT favors fear-related responses; this fact is also an accepted finding in studies conducted with healthy participants (Domes et al., 2010).

The above inconsistency can be understood in light of Heinrichs et al. (2004). These authors argue that OXT can produce an extinction effect on aversive memories among healthy participants, depending on the test type used and the relevance of the stimuli to the evaluated patient. According to their findings and the previous literature (Kirsch et al., 2005; Domes et al., 2007; Gamer et al., 2010), the effects of OXT on amygdala reactivity might differ not only because of inter-individual factors such as gender and level of psychopathology but also because of the context (i.e., the emotional content/valence of the stimulus).

The increased number of flashbacks suggests that the administration of OXT in individuals who experienced recent trauma impedes the functioning of the emotional regulation network in response to exposure to situations reminiscent of the trauma. This finding is contrary to the previous literature (Koch et al., 2016b; Sack et al., 2017) showing the potential role that OXT plays in the extinction of traumatic memories. In previous studies, postpartum women (i.e., those with increased OXT production) experience temporary deficits in memory that contribute to the extinction of the aversive memories associated with childbirth (Brindle et al., 1991; Brett and Baxendale, 2001).

On the other hand, the continuous use of OXT for 8 days had positive effects only for individuals with severe symptoms/traumas, again suggesting an interdependence of inter-individual variables. Thus, the studies of the use of OXT to prevent PTSD suggest the need for caution because of the possible negative/anxiogenic effects on the one hand and the presence of benefits resulting from OXT administration that occur selectively only in highly symptomatic individuals on the other.
Finally, for individuals with PTSD, the effects of acute OXT administration were favorable. Considering that PTSD is associated with hyperactivity in the amygdala and other limbic brain structures when presented with negative emotional stimuli (Brunetti et al., 2010; Frijling, 2017), OXT favored the reestablishment of the functioning of different neural networks associated with fear control and extinction responses, thereby favoring better emotional control and cognitive performance through the reduction of hypervigilance, avoidance, anhedonia, and emotional salience to fear.

Importantly, these studies showed weak effects for the control groups that were composed mostly of participants with RTEs (i.e., those exposed to trauma but without PTSD). This result reinforces the findings of the previous group of studies that indicated the lack of benefits for this specific sample. These data also reinforce the positions of Koch et al. $(2016 \mathrm{a}, \mathrm{b})$ and Bartz et al. (2010) who argued that OXT is beneficial only for individuals with impaired fear regulation and social functioning. However, Palgi et al. (2016) examined participants exposed to trauma, with or without PTSD, and found that they benefited from the administration of OXT in terms of their compassion response.

Regarding the studies related to the different polymorphisms, the present review suggested that variations and polymorphisms are intrinsically associated with the changes in the stress resilience mechanism and the experience of traumatic experiences (Cicchetti and Rogosch, 2012). One possible explanation is that individuals with polymorphic variations in the OXT receptor gene due to random changes in the position of the amino acids are more vulnerable to the development of disorders resulting from traumatic experiences throughout the lifespan (Feldman et al., 2016).

The genetic polymorphisms that showed more damage were those associated with the GG genotype at the OXT genetic receptors rs53576, rs139832701, and rs11131147. These genetic variations might alter receptor configuration and develop changes at density, alter the number of receptors available in the central nervous system (Champagne and Curley, 2009; Skuse and Gallagher, 2011), and might develop alterations on OXT binding affinity to the receptor, thereby altering the effects/functions of OXT in the body.

Interestingly, Dannlowski et al. (2016) found that the presence of the GG genotype allied with ET might increase the vulnerability to the greater activation of limbic areas during the visualization of positive/negative faces; however, these authors indicated that such a vulnerability would also depend on environmental experiences and the complex interaction between genes and environment. Therefore, stable environments should provide more positive signals and lead to beneficial development, whereas threatening environments should result in detrimental effects on emotional development and lead to vulnerability to psychiatric disorders.

Champagne and Curley (2009) also suggested that participants exposed to stressful environments undergo DNA methylation processes that modify the positions of nitrogenous bases, thereby resulting in the modification of certain gene expression. Therefore, the binding affinity of OXT to the 
receptor might be altered, thereby reducing the amount of bound OXT and leading to a reduction in the function of OXT in the organism. This effect would alter the individual's vulnerability to the effects of stress (Jack et al., 2012).

On the other hand, one study (Sippel et al., 2017) indicated that polymorphisms on the OXTR rs53576 receptor gene with the presence of a single A' allele might contribute to the formation of insecure attachments among individuals with PTSD. This finding is relevant because this attachment style is associated with a reduced response to PTSD treatment. Such dysfunction might translate into a neural mechanism that could predispose individuals to negative assessments of their social environment stimuli, which might compromise the stress-reducing effects of social support and exacerbate the effect of cognitive representations of relationships as threatening, mistrustful, or unstable.

Finally, the other genetic polymorphisms (OXTR rs2254298 and rs2268498) had no effect on PTSD symptoms or their development (Dunn et al., 2014) nor on the depression or anxiety symptoms of participants with ET (Tollenaar et al., 2017). One possible explanation is that the participants were recruited from a specific population of low-income non-Hispanics blacks who were exposed to Hurricane Katrina (Dunn et al. 2014) or healthy participants with ET (Tollenaar et al., 2017). Large samples are required for candidate gene studies.

\section{CONCLUDING REMARKS}

This systematic review regarding the relationship between OXT and emotional trauma in humans revealed that reductions in endogenous OXT levels are more strongly associated with the presence of severe and recurrent ET and PTSD.

The results also show that the acute effect of OXT in victims of ET tends to be anxiolytic, but only in those with less severe forms of ET. Among individuals with severe ET, OXT does not seem to have anxiolytic properties and may even increase anxiety. The same holds true for victims of RTE, since OXT has been reported to increase the re-experience of traumatic symptoms. In patients with PTSD, OXT reestablished the function of different neural networks associated with fear control and extinction.

Genetic studies showed that the presence of the GG genotype in the OXTR rs53576 gene polymorphism associated with the experience of ET or PTSD is related to more negative outcomes, whereas the presence of the AA genotype appears to have a protective role.

\section{REFERENCES}

Altemus, M., Roca, C., Galliven, E., Romanos, C., and Deuster, P. (2001). Increased vasopressin and adrenocorticotropin responses to stress in the midluteal phase of the menstrual cycle. J. Clin. Endocrinol. Metabol. 86, 2525-2530. doi: $10.1210 /$ jcem.86.6.7596
It should be noted that the relationship between OXT and traumatic situations is mediated by different contextual and inter-individual variables that might predict more or less favorable outcomes. Thus, a stable environment, less severe forms of trauma, and the female gender are associated with resiliency responses.

The studies included in the review have limitations that call for caution in the interpretation and generalization of their findings, including (a) small sample sizes recruited from extremely specific contexts; (b) poor control of confounding variables such as gender and ET severity; (c) highly variable age groups; (d) crosssectional designs; (e) possible differences between chronic and acute administration of OXT in RCT; and (f) lack of evaluation of both central and peripheral levels of OXT to determine whether differences exist [most of the studies on this topic assessed endogenous levels in peripheral fluids (e.g., blood plasma, urine, saliva) and the methodological validity of these techniques is controversial (Wotjak et al., 1998; Seltzer et al., 2014; Valstad et al., 2017)].

For future studies, we suggest the adoption of longitudinal designs to establish causal relationships; the recruitment of large samples to control for gender, age, and sex hormones; the conduction of RCTs with chronic and/or prolonged administration of OXT; the investigation of other polymorphisms that might interfere with or contribute to increased susceptibility to the harmful effects of traumatic experiences; and the performance of epigenetic investigations on the association between ET, RTE, and PTSD with OXT.

\section{AUTHOR CONTRIBUTIONS}

All authors listed have made a substantial, direct and intellectual contribution to the work, and approved it for publication.

\section{ACKNOWLEDGMENTS}

The National Council for Technological and Scientific Development (CNPq grant numbers 2015/12548-6 and 301321/2016-7), the Spanish Biomedical Research Networking Center for Mental Health (CIBERSAM), and the Comission at per a Universitats i Recerca del DIUE, Generalitat de Catalunya, Spain (grant number 2014SGR1435) supported this study.

\section{SUPPLEMENTARY MATERIAL}

The Supplementary Material for this article can be found online at: https:/www.frontiersin.org/articles/10.3389/fphar. 2018.00154/full\#supplementary-material

Amico, J. A., Mantella, R. C., Vollmer, R. R., and Li, X. (2004). Anxiety and stress responses in female oxytocin deficient mice. J. Neuroendocrinol. 16, 319-324. doi: 10.1111/j.0953-8194.2004.01161.x

Bakermans-Kranenburg, M. J., and van IJzendoorn, M. H. (2014). A sociability gene? Meta-analysis of oxytocin receptor genotype effects in humans. Psychiatr. Genet. 24, 45-51. doi: 10.1097/YPG.0b013e3283643684 
Bartz, J. A., Zaki, J., Bolger, N., Hollander, E., Ludwig, N. N., Kolevzon, A., et al. (2010). Oxytocin selectively improves empathic accuracy. Psychol. Sci. 21, 1426-1428. doi: 10.1177/0956797610383439

Boyce, W. T., and Ellis, B. (2005). Biological sensitivity to context: I. An evolutionary-developmental theory of the origins and functions of stress reactivity. Dev. Psychopathol. 17, 271-301. doi: 10.1017/S0954579405050145

Bradley, B., Westen, D., Mercer, K. B., Binder, E. B., Jovanovic, T., Crain, D., et al. (2011). Association between childhood maltreatment and adult emotional dysregulation in a low-income, urban, African American sample: moderation by oxytocin receptor gene. Dev. Psychopathol. 23, 439-452. doi: 10.1017/S0954579411000162

Bremner, J. D., Vermetten, E., and Mazure, C. M. (2000). Development and preliminary psychometric properties of an instrument for the measurement of childhood trauma: the early trauma inventory. Depress Anxiety 12, 1-12. doi: 10.1002/1520-6394(2000)12:1<1::AID-DA1>3.0.CO;2-W

Brett, M., and Baxendale, S. (2001). Motherhood and memory: a review. Psychoneuroendocrinology 26, 339-362. doi: 10.1016/S0306-4530(01)00003-8

Brindle, P. M., Brown, M. W., Brown, J., Griffith, H. B., and Turner, G. M. (1991). Objective and subjective memory impairment in pregnancy. Psychol. Med. 21, 647-653. doi: 10.1017/S0033291700022285

Brown, C. A., Cardoso, C., and Ellenbogen, M. A. (2016). A meta-analytic review of the correlation between peripheral oxytocin and cortisol concentrations. Front. Neuroendocrinol. 43, 19-27. doi: 10.1016/j.yfrne.2016.11.001

Brunetti, M., Sepede, G., Mingoia, G., Catani, C., Ferretti, A., Merla, A., et al. (2010). Elevated response of human amygdala to neutral stimuli in mild post traumatic stress disorder: neural correlates of generalized emotional response. Neuroscience 168, 670-679. doi: 10.1016/j.neuroscience.2010.04.024

Cameron, N. M., Fish, E. W., and Meaney, M. J. (2008). Maternal influences on the sexual behavior and reproductive success of the female rat. Horm. Behav. 54, 178-184. doi: 10.1016/j.yhbeh.2008.02.013

Cardoso, C., Ellenbogen, M. A., Orlando, M. A., Bacon, S. L., and Joober, R. (2013). Intranasal oxytocin attenuates the cortisol response to physical stress: a dose-response study. Psychoneuroendocrinology 38, 399-407. doi: 10.1016/j.psyneuen.2012.07.013

Cardoso, C., Kingdon, D., and Ellenbogen, M. A. (2014). A meta-analytic review of the impact of intranasal oxytocin administration on cortisol concentrations during laboratory tasks: moderation by method and mental health. Psychoneuroendocrinology 49, 161-170. doi: 10.1016/j.psyneuen.2014.07.014

Carpenter, L. L., Tyrka, A. R., Ross, N. S., Khoury, L., Anderson, G. M., and Price, L. H. (2009). Effect of childhood emotional abuse and age on cortisol responsivity in adulthood. Biol. Psychiatry 66, 69-75. doi: 10.1016/j.biopsych.2009.02.030

Champagne, F. A., and Curley, J. P. (2009). Epigenetic mechanisms mediating the long-term effects of maternal care on development. Neurosci. Biobehav. Rev. 33, 593-600. doi: 10.1016/j.neubiorev.2007.10.009

Chatzittofis, A., Nordström, P., Uvnäs-Moberg, K., Åsberg, M., and Jokinen, J. (2014). CSF and plasma oxytocin levels in suicide attempters, the role of childhood trauma and revictimization. Neuro Endocrinol. Lett. 35, 213-217.

Cicchetti, D., and Rogosch, F. A. (2012). Gene and Environment interaction and resilience: effects of child maltreatment and serotonin, corticotropin releasing hormone, dopamine, and oxytocin genes. Dev. Psychopathol. 24, 411-427. doi: 10.1017/S0954579412000077

Dannlowski, U., Kugel, H., Grotegerd, D., Redlich, R., Opel, N., Dohm, K., et al. (2016). Disadvantage of social sensitivity: interaction of oxytocin receptor genotype and child maltreatment on brain structure. Biol. Psychiatry 80, 398-405. doi: 10.1016/j.biopsych.2015.12.010

Des Jarlais, D. C., Lyles, C., and Crepaz, N. (2004). Improving the reporting quality of nonrandomized evaluations of behavioral and public health interventions: the TREND statement. Am. J. Public Health 94, 361-366. doi: 10.2105/AJPH.94.3.361

Domes, G., Heinrichs, M., Gläscher, J., Büchel, C., Braus, D. F., and Herpertz, S. C. (2007). Oxytocin attenuates amygdala responses to emotional faces regardless of valence. Biol. Psychiatry 62, 1187-1190. doi: 10.1016/j.biopsych.2007.03.025

Domes, G., Lischke, A., Berger, C., Grossmann, A., Hauenstein, K., Heinrichs, M., et al. (2010). Effects of intranasal oxytocin on emotional face processing in women. Psychoneuroendocrinology 35, 83-93. doi: 10.1016/j.psyneuen.2009.06.016

Dunn, E. C., Solovieff, N., Lowe, S. R., Gallagher, P. J., Chaponis, J., Rosand, J., et al. (2014). Interaction between genetic variants and exposure to
Hurricane Katrina on post-traumatic stress and post-traumatic growth: a prospective analysis of low income adults. J. Affect. Disord. 152, 243-249. doi: 10.1016/j.jad.2013.09.018

Ebner, K., Wotjak, C. T., Landgraf, R., and Engelmann, M. (2000). A single social defeat experience selectively stimulates the release of oxytocin, but not vasopressin, within the septal brain area of male rats. Brain Res. 872, 87-92. doi: 10.1016/S0006-8993(00)02464-1

Eidelman-Rothman, M., Goldstein, A., Levy, J., Weisman, O., Schneiderman, I., Mankuta, D., et al. (2015). Oxytocin affects spontaneous neural oscillations in trauma-exposed war veterans. Front. Behav. Neurosci. 9:165. doi: 10.3389/fnbeh.2015.00165

Elzinga, B. M., Roelofs, K., Tollenaar, M. S., Bakvis, P., van Pelt, J., and Spinhoven, P. (2008). Diminished cortisol responses to psychosocial stress associated with lifetime adverse events: a study among healthy young subjects. Psychoneuroendocrinology 33, 227-237. doi: 10.1016/j.psyneuen.2007.11.004

Fan, Y., Herrera-Melendez, A. L., Pestke, K., Feeser, M., Aust, S., Otte, C., et al. (2014). Early life stress modulates amygdala-prefrontal functional connectivity: implications for oxytocin effects. Hum. Brain Mapp. 35, 5328-5339. doi: 10.1002/hbm.22553

Faravelli, C., Sauro, C. L., Godini, L., Lelli, L., Benni, L., Pietrini, F., et al. (2012). Childhood stressful events, HPA axis and anxiety disorders. World J. Psychiatry 2, 13-25. doi: 10.5498/wjp.v2.i1.13

Feldman, R., Monakhov, M., Pratt, M., and Ebstein, R. P. (2016). Oxytocin pathway genes: evolutionary ancient system impacting on human affiliation, sociality, and psychopathology. Biol. Psychiatry 79, 174-184. doi: 10.1016/j.biopsych.2015.08.008

Feng, C., Hackett, P. D., DeMarco, A. C., Chen, X., Stair, S., Haroon, E., et al. (2015). Oxytocin and vasopressin effects on the neural response to social cooperation are modulated by sex in humans. Brain Imaging Behav. 9, 754-764. doi: 10.1007/s11682-014-9333-9

Finkelhor, D., Hotaling, G., Lewis, I., and Smith, C. (1990). Sexual abuse in a national survey of adult men and women: prevalence, characteristics, and risk factors. Child Abuse Negl. 14, 19-28. doi: 10.1016/0145-2134(90)90077-7

Fischer-Shofty, M., Shamay-Tsoory, S. G., Harari, H., and Levkovitz, Y. (2010). The effect of intranasal administration of oxytocin on fear recognition. Neuropsychologia 48, 179-184. doi: 10.1016/j.neuropsychologia.2009. 09.003

Frijling, J. L. (2017). Preventing PTSD with oxytocin: effects of oxytocin administration on fear neurocircuitry and PTSD symptom development in recently trauma-exposed individuals. Eur. J. Psychotraumatol. 8:1302652. doi: 10.1080/20008198.2017.1302652

Frijling, J. L., van Zuiden, M., Koch, S. B., Nawijn, L., Veltman, D. J., and Olff, M. (2016a). Intranasal oxytocin affects amygdala functional connectivity after trauma script-driven imagery in distressed recently trauma-exposed individuals. Neuropsychopharmacology 41, 1286-1296 doi: $10.1038 /$ npp.2015.278

Frijling, J. L., van Zuiden, M., Koch, S. B., Nawijn, L., Veltman, D. J., and Olff, M. (2016b). Effects of intranasal oxytocin on amygdala reactivity to emotional faces in recently trauma-exposed individuals. Soc. Cogn. Affect. Neurosci. 17, 327-336. doi: 10.1093/scan/nsv116

Frijling, J. L., Zuiden, M., Nawijn, L., Koch, S. B. J., Neumann, I. D., Veltman, D. J., et al. (2015). Salivary oxytocin and vasopressin levels in police officers with and without post traumatic stress disorder. J. Neuroendocrinol. 27, 743-751. doi: $10.1111 /$ jne. 12300

Gamer, M., Zurowski, B., and Büchel, C. (2010). Different amygdala subregions mediate valence-related and attentional effects of oxytocin in humans. Proc. Natl. Acad. Sci. U.S.A. 107, 9400-9405. doi: 10.1073/pnas.1000985107

Gimpl, G., and Fahrenholz, F. (2001). The oxytocin receptor system: structure, function, and regulation. Physiol. Rev. 81, 629-683. doi: 10.1152/physrev.2001.81.2.629

Goldman-Mellor, S., Hamer, M., and Steptoe, A. (2012). Early-life stress and recurrent psychological distress over the lifecourse predict divergent cortisol reactivity patterns in adulthood. Psychoneuroendocrinology 37, 1755-1768. doi: 10.1016/j.psyneuen.2012.03.010

Gonzalez, A., Jenkins, J. M., Steiner, M., and Fleming, A. S. (2009). The relation between early life adversity, cortisol awakening response and diurnal salivary cortisol levels in postpartum women. Psychoneuroendocrinology 34, 76-86. doi: 10.1016/j.psyneuen.2008.08.012 
Grimm, S., Pestke, K., Feeser, M., Aust, S., Weigand, A., Wang, J., et al. (2014). Early life stress modulates oxytocin effects on limbic system during acute psychosocial stress. Soc. Cogn. Affect. Neurosci. 9, 1828-1835. doi: $10.1093 / \mathrm{scan} / \mathrm{nsu} 020$

Guastella, A. J., Howard, A. L., Dadds, M. R., Mitchell, P., and Carson, D. S. (2009). A randomized controlled trial of intranasal oxytocin as an adjunct to exposure therapy for social anxiety disorder. Psychoneuroendocrinology 34, 917-923. doi: 10.1016/j.psyneuen.2009.01.005

Gulpinar, M. A., and Yegen, B. C. (2004). The physiology of learning and memory: role of peptides and stress. Curr. Protein Pept. Sci. 5, 457-473. doi: 10.2174/1389203043379341

Heim, C., Newport, D. J., Heit, S., Graham, Y. P., Wilcox, M., Bonsall, R., et al. (2000). Pituitary-adrenal and autonomic responses to stress in women after sexual and physical abuse in childhood. J. Am. Med. Assoc. 284, 592-597. doi: 10.1001/jama.284.5.592

Heim, C., Young, L. J., Newport, D. J., Mletzko, T., Miller, A. H., and Nemeroff, C. B. (2009). Lower CSF oxytocin concentrations in women with a history of childhood abuse. Mol. Psychiatry 14, 954-958. doi: 10.1038/mp.2008.112

Heinrichs, M., Baumgartner, T., Kirschbaum, C., and Ehlert, U. (2003). Social support and oxytocin interact to suppress cortisol and subjective responses to psychosocial stress. Biol. Psychiatry 54, 1389-1398. doi: 10.1016/S0006-3223(03)00465-7

Heinrichs, M., Meinlschmidt, G., Wippich, W., Ehlert, U., and Hellhammer, D. H. (2004). Selective amnesic effects of oxytocin on human memory. Physiol. Behav. 83, 31-38. doi: 10.1016/S0031-9384(04)00346-4

Hoge, E. A., Anderson, E., Lawson, E. A., Bui, E., Fischer, L. E., Khadge, S. D., et al. (2014). Gender moderates the effect of oxytocin on social judgments. Hum. Psychopharmacol. Clin. Exp. 29, 299-304. doi: 10.1002/hup.2402

Hostinar, C. E., Cicchetti, D., and Rogosch, F. A. (2014). Oxytocin receptor gene polymorphism, perceived social support, and psychological symptoms in maltreated adolescents. Dev. Psychopathol. 26, 465-477. doi: $10.1017 /$ S0954579414000066

Jack, A., Connelly, J. J., and Morris, J. P. (2012). DNA methylation of the oxytocin receptor gene predicts neural response to ambiguous social stimuli. Front. Hum. Neurosci. 6:280. doi: 10.3389/fnhum.2012.00280

Juruena, M. F., Clearea, A. J., and Pariantea, C. M. (2004). O eixo hipotálamo-pituitária-adrenal, a função dos receptores de glicocorticóides e sua importância na depressão The hypothalamic pituitary adrenal axis, glucocorticoid receptor function and relevance to. Rev. Bras. Pisquiatr. 26, 189-201. doi: 10.1590/S1516-44462004000300009

Kirsch, P., Esslinger, C., Chen, Q., Mier, D., Lis, S., Siddhanti, S., et al. (2005). Oxytocin modulates neural circuitry for social cognition and fear in humans. J. Neurosci. 25, 11489-11493. doi: 10.1523/JNEUROSCI.3984-05.2005

Koch, S. B., van Zuiden, M., Nawijn, L., Frijling, J. L., Veltman, D. J., and Olff, M. (2016a). Intranasal oxytocin administration dampens amygdala reactivity towards emotional faces in male and female PTSD patients. Neuropsychopharmacology 41, 1495-1504. doi: 10.1038/npp.2015.299

Koch, S. B., van Zuiden, M., Nawijn, L., Frijling, J. L., Veltman, D. J., and Olff, M. (2016b). Intranasal oxytocin normalizes amygdala functional connectivity in post-traumatic stress disorder. Neuropsychopharmacology 41, 2041-2051. doi: $10.1038 /$ npp. 2016.1

Kuhlman, K. R., Vargas, I., Geiss, E. G., and Lopez-Duran, N. L. (2015). Age of trauma onset and HPA axis dysregulation among trauma exposed youth. $J$. Trauma. Stress 28, 572-579. doi: 10.1002/jts.22054

Lucas-Thompson, R. G., and Holman, E. A. (2013). Environmental stress, oxytocin receptor gene (OXTR) polymorphism, and mental health following collective stress. Horm. Behav. 63, 615-624. doi: 10.1016/j.yhbeh.2013.02.015

McQuaid, R. J., McInnis, O. A., Paric, A., Al-Yawer, F., Matheson, K., and Anisman, H. (2016). Relations between plasma oxytocin and cortisol: the stress buffering role of social support. Neurobiol. Stress 3, 52-60. doi: 10.1016/j.ynstr.2016.01.001

McQuaid, R. J., McInnis, O. A., Stead, J. D., Matheson, K., and Anisman, H. (2013). A paradoxical association of an oxytocin receptor gene polymorphism: early-life adversity and vulnerability to depression. Front. Neurosci. 7:128. doi: $10.3389 /$ fnins.2013.00128

Meewisse, M. L., Reitsma, J. B., De Vries, G. J., Gersons, B. P., and Olff, M. (2007). Cortisol and post-traumatic stress disorder in adults. Br. J. Psychiatry 191, 387-392. doi: 10.1192/bjp.bp.106.024877
Meinlschmidt, G., and Heim, C. (2007). Sensitivity to intranasal oxytocin in adult men with early parental separation. Biol. Psychiatry 61, 1109-1111. doi: 10.1016/j.biopsych.2006.09.007

Mirescu, C., Peters, J. D., and Gould, E. (2004). Early life experience alters response of adult neurogenesis to stress. Nat. Neurosci. 7, 841-846. doi: 10.1038/nn1290

Mizuki, R., and Fujiwara, T. (2015). Association of oxytocin level and less severe forms of childhood maltreatment history among healthy Japanese adults involved with child care. Front. Behav. Neurosci. 9:138. doi: 10.3389/fnbeh.2015.00138

Mizushima, S. G., Fujisawa, T. X., Takiguchi, S., Kumazaki, H., Tanaka, S., and Tomoda, A. (2015). Effect of the nature of subsequent environment on oxytocin and cortisol secretion in maltreated children. Front. Psychiatry 6:173. doi: $10.3389 /$ fpsyt.2015.00173

Moher, D., Liberati, A., and Tetzlaff, J. (2009). Preferred reporting items for systematic reviews and meta-analyses: the PRISMA statement. PLoS Med. 6:e1000097. doi: 10.1371/journal.pmed.1000097

Moher, D., Schulz, K. F., and Altman, D. G. (2001). The CONSORT statement: revised recommendations for improving the quality of reports of parallel-group randomised trials. Lancet 357, 1191-1194. doi: 10.1016/S0140-6736(00)04337-3

Mohiyeddini, C., Opacka-Juffry, J., and Gross, J. J. (2014). Emotional suppression explains the link between early life stress and plasma oxytocin. Anxiety Stress Coping 27, 466-475. doi: 10.1080/10615806.2014.887696

Munro, M. L., Brown, S. L., Pournajafi-Nazarloo, H., Carter, C. S., Lopez, W. D., and Seng, J. S. (2013). In search of an adult attachment stress provocation to measure effect on the oxytocin system a pilot validation study. J. Am. Psychiatr. Nurses Assoc. 19, 180-191. doi: 10.1177/10783903134 92173

Myers, A. J., Williams, L., Gatt, J. M., McAuley-Clark, E. Z., Dobson-Stone, C., Schofield, P. R., et al. (2014). Variation in the oxytocin receptor gene is associated with increased risk for anxiety, stress and depression in individuals with a history of exposure to early life stress. J. Psychiatr. Res. 59, 93-100. doi: 10.1016/j.jpsychires.2014.08.021

Nawijn, L., van Zuiden, M., Koch, S. B., Frijling, J. L., Veltman, D. J., and Olff, M. (2016). Intranasal oxytocin enhances neural processing of monetary reward and loss in post-traumatic stress disorder and traumatized controls. Psychoneuroendocrinology 66, 228-237. doi: 10.1016/j.psyneuen.2016. 01.020

Nawijn, L., van Zuiden, M., Koch, S. B., Frijling, J. L., Veltman, D. J., and Olff, M. (2017). Intranasal oxytocin increases neural responses to social reward in post-traumatic stress disorder. Soc. Cogn. Affect. Neurosci. 12, 212-223. doi: $10.1093 /$ scan/nsw123

Neumann, I. D., and Landgraf, R. (2012). Balance of brain oxytocin and vasopressin: implications for anxiety, depression, and social behaviors. Trends Neurosci. 35, 649-659. doi: 10.1016/j.tins.2012.08.004

Nicolson, N. A., Davis, M. C., Kruszewski, D., and Zautra, A. J. (2010). Childhood maltreatment and diurnal cortisol patterns in women with chronic pain Psychosom. Med. 72, 471-480. doi: 10.1097/PSY.0b013e3181d9a104

Nishi, D., Hashimoto, K., Noguchi, H., Kim, Y., and Matsuoka, Y. (2015). Serum oxytocin, posttraumatic coping and C-reactive protein in motor vehicle accident survivors by gender. Neuropsychobiology 71, 196-201. doi: $10.1159 / 000382021$

Olff, M. (2012). Bonding after trauma: on the role of social support and the oxytocin system in traumatic stress. Eur. J. Psychotraumatol. 3:18597. doi: $10.3402 /$ ejpt.v3i0.18597

Opacka-Juffry, J., and Mohiyeddini, C. (2012). Experience of stress in childhood negatively correlates with plasma oxytocin concentration in adult men. Stress 15, 1-10. doi: 10.3109/10253890.2011.560309

Ozbay, F., Fitterling, H., Charney, D., and Southwick, S. (2008). Social support and resilience to stress across the life span: a neurobiologic framework. Curr. Psychiatry Rep. 10, 304-310. doi: 10.1007/s11920-008-0049-7

Palgi, S., Klein, E., and Shamay-Tsoory, S. G. (2016). Oxytocin improves compassion toward women among patients with PTSD. Psychoneuroendocrinology 64, 143-149. doi: 10.1016/j.psyneuen.2015.11.008

Pierrehumbert, B., Torrisi, R., Laufer, D., Halfon, O., Ansermet, F., and Popovic, M. B. (2010). Oxytocin response to an experimental psychosocial challenge in adults exposed to traumatic experiences during childhood or adolescence. Neuroscience 166, 168-177. doi: 10.1016/j.neuroscience.2009.12.016 
Reijnen, A., Geuze, E., and Vermetten, E. (2017). Individual variation in plasma oxytocin and vasopressin levels in relation to the development of combat-related PTSD in a large military cohort. J. Psychiatr. Res. 94, 88-95. doi: 10.1016/j.jpsychires.2017.06.010

Rimmele, U., Hediger, K., Heinrichs, M., and Klaver, P. (2009). Oxytocin makes a face in memory familiar. J. Neurosci. 29, 38-42. doi: 10.1523/JNEUROSCI.4260-08.2009

Ring, R. H., Malberg, J. E., Potestio, L., Ping, J., Boikess, S., Luo, B., et al. (2006). Anxiolytic-like activity of oxytocin in male mice: behavioral and autonomic evidence, therapeutic implications. Psychopharmacology 185, 218-225. doi: 10.1007/s00213-005-0293-z

Ross, H. E., and Young, L. J. (2009). Oxytocin and the neural mechanisms regulating social cognition and affiliative behavior. Front. Neuroendocrinol. 30, 534-547. doi: 10.1016/j.yfrne.2009.05.004

Sack, M., Cillien, M., and Hopper, J. W. (2012). Acute dissociation and cardiac reactivity to script-driven imagery in trauma-related disorders. Eur. J. Psychotraumatol. 3:17419. doi: 10.3402/ejpt.v3i0.17419

Sack, M., Spieler, D., Wizelman, L., Epple, G., Stich, J., Zaba, M., et al. (2017). Intranasal oxytocin reduces provoked symptoms in female patients with posttraumatic stress disorder despite exerting sympathomimetic and positive chronotropic effects in a randomized controlled trial. BMC Med. 15:40. doi: 10.1186/s12916-017-0801-0

Savaskan, E., Ehrhardt, R., Schulz, A., Walter, M., and Schächinger, H. (2008). Post-learning intranasal oxytocin modulates human memory for facial identity. Psychoneuroendocrinology 33, 368-374. doi: 10.1016/j.psyneuen.2007.12.004

Seltzer, L. J., Ziegler, T., Connolly, M. J., Prososki, A. R., and Pollak, S. D. (2014). Stress-induced elevation of oxytocin in maltreated children: evolution, neurodevelopment, and social behavior. Child Dev. 85, 501-512. doi: $10.1111 /$ cdev.12136

Seng, J. S. (2010). Posttraumatic oxytocin dysregulation: is it a link among posttraumatic self disorders, posttraumatic stress disorder, and pelvic visceral dysregulation conditions in women?. J. Trauma Dissoc. 11, 387-406. doi: $10.1080 / 15299732.2010 .496075$

Seng, J. S., D'andrea, W., and Ford, J. D. (2014). Complex mental health sequelae of psychological trauma among women in prenatal care. Psychol. Trauma 6, 41-49. doi: 10.1037/a0031467

Sippel, L. M., Han, S., Watkins, L. E., Harpaz-Rotem, I., Southwick, S. M., Krystal, J. H., et al. (2017). Oxytocin receptor gene polymorphisms, attachment, and PTSD: results from the national health and resilience in veterans study. $J$. Psychiatr. Res. 94, 139-147. doi: 10.1016/j.jpsychires.2017.07.008

Skuse, D. H., and Gallagher, L. (2011). Genetic influences on social cognition. Pediatr. Res. 69, 85-91. doi: 10.1203/PDR.0b013e318212f562

Smith, S. M., and Vale, W. W. (2006). The role of the hypothalamic-pituitaryadrenal axis in neuroendocrine responses to stress. Dialog. Clin. Neurosci. 8, 383-395.

Taylor, S. E., Gonzaga, G. C., Klein, L. C., Hu, P., Greendale, G. A., and Seeman, T. E. (2006). Relation of oxytocin to psychological stress responses and hypothalamic-pituitary-adrenocortical axis activity in older women. Psychosom. Med. 68, 238-245. doi: 10.1097/01.psy.0000203242.95990.74

Tollenaar, M. S., Molendijk, M. L., Penninx, B. W., Milaneschi, Y., and Antypa, N. (2017). The association of childhood maltreatment with depression and anxiety is not moderated by the oxytocin receptor gene. Eur. Arch. Psychiatry Clin. Neurosci. 267, 517-526. doi: 10.1007/s00406-017-0784-z

Uhl-Bronner, S., Waltisperger, E., Martínez-Lorenzana, G., Condes, L. M., and Freund-Mercier, M. J. (2005). Sexually dimorphic expression of oxytocin binding sites in forebrain and spinal cord of the rat. Neuroscience 135, 147-154. doi: 10.1016/j.neuroscience.2005.05.025
Unternaehrer, E., Luers, P., Mill, J., Dempster, E., Meyer, A. H., and Staehli, S. (2012). Dynamic changes in DNA methylation of stress-associated genes (OXTR, BDNF) after acute psychosocial stress. Transl. Psychiatry 2:e150. doi: $10.1038 /$ tp.2012.77

Valstad, M., Alvares, G. A., Egknud, M., Matziorinis, A. M., Andreassen, O. A., Westlye, L. T., et al. (2017). The correlation between central and peripheral oxytocin concentrations: a systematic review and meta-analysis. Neurosci. Biobehav. Rev. 78, 117-124. doi: 10.1016/j.neubiorev.2017.04.017

Van Zuiden, M., Frijling, J. L., Nawijn, L., Koch, S. B., Goslings, J. C., Luitse, J. S., et al. (2017). Intranasal oxytocin to prevent posttraumatic stress disorder symptoms: a randomized controlled trial in emergency department patients. Biol. Psychiatry 81, 1030-1040. doi: 10.1016/j.biopsych.2016. 11.012

Veenema, A. H. (2012). Toward understanding how early-life social experiences alter oxytocin-and vasopressin-regulated social behaviors. Horm. Behav. 61, 304-312. doi: 10.1016/j.yhbeh.2011.12.002

Von Elm, E., Altman, D. G., Egger, M., Pocock, S. J., Gotzsche, P. C., and Vandenbroucke, J. P. (2007). The Strengthening the Reporting of Observational Studies in Epidemiology (STROBE) statement: guidelines for reporting observational studies. Prev. Med. 45, 247-251. doi: 10.1016/j.ypmed.2007.08.012

Wigger, A., and Neumann, I. D. (1999). Periodic maternal deprivation induces gender-dependent alterations in behavioral and neuroendocrine responses to emotional stress in adult rats. Physiol. Behav. 66, 293-302. doi: 10.1016/S0031-9384(98)00300-X

Williams, T. D. M., Carter, D. A., and Lightman, S. L. (1985). Sexual dimorphism in the posterior pituitary response to stress in the rat. Endocrinology 116, 738-740. doi: 10.1210/endo-116-2-738

Wotjak, C. T., Ganster, J., Kohl, G., Holsboer, F., Landgraf, R., and Engelmann, M. (1998). Dissociated central and peripheral release of vasopressin, but not oxytocin, in response to repeated swim stress: new insights into the secretory capacities of peptidergic neurons. Neuroscience 85, 1209-1222. doi: 10.1016/S0306-4522(97)00683-0

Yehuda, R., Bierer, L. M., Schmeidler, J., Aferiat, D. H., Breslau, I., and Dolan, S. (2000). Low cortisol and risk for PTSD in adult offspring of holocaust survivors. Am. J. Psychiatry 157, 1252-1259. doi: 10.1176/appiajp.157. 8.1252

Yoshida, M., Takayanagi, Y., Inoue, K., Kimura, T., Young, L. J., Onaka, T., et al. (2009). Evidence that oxytocin exerts anxiolytic effects via oxytocin receptor expressed in serotonergic neurons in mice. J. Neurosci. 29, 2259-2271. doi: 10.1523/JNEUROSCI.5593-08.2009

Young, L. J., Muns, S., Wang, Z., and Insel, T. R. (1997). Changes in oxytocin receptor mRNA in rat brain during pregnancy and the effects of estrogen and interleukin. J. Neuroendocrinol. 9, 859-865. doi: 10.1046/j.1365-2826.1997.00654.x

Conflict of Interest Statement: The authors declare that the research was conducted in the absence of any commercial or financial relationships that could be construed as a potential conflict of interest.

Copyright (๑) 2018 Donadon, Martin-Santos and Osório. This is an open-access article distributed under the terms of the Creative Commons Attribution License (CC $B Y)$. The use, distribution or reproduction in other forums is permitted, provided the original author(s) and the copyright owner are credited and that the original publication in this journal is cited, in accordance with accepted academic practice. No use, distribution or reproduction is permitted which does not comply with these terms. 